\title{
Introduction: what are the issues now? Controversies about disequilibria, economic growth and economic policies
}

\section{Noemi Levy and Etelberto Ortiz}

Mainstream economic theory and economic policy actions are based on an intellectual approach that establishes economic equilibrium as the central reference point around which economic and social processes are discussed, particularly the mechanisms that generate economic growth and redistribution of profits (Lucas, 1976; Goodfriend, 2002; Woodford, 2003). The major limitation of this theoretical approach is that it cannot account for changes in direction, or indicate how economic conditions change (Hicks, 1946; De Vroey, 1999); the use of comparative statics, in an ideal case, enables analysis of the change from one state of equilibrium to another. However, it does not explain the transition from one position to another over time (Woodford, 2003). Of particular importance to the situation currently facing the international economic system is the dismissal or improper interpretation of financial disequilibria (see Woodford, 2009).

The major changes to the dominant theory, presented today by the New Macroeconomic Consensus (Woodford, 2003), are, first, a greater mathematical formalization and sophistication that does not offer explanations of the dynamic nature of the capitalist economy and, therefore, this perspective still fails to provide consistent arguments about the nature of the phenomena that supposedly established a balanced trajectory. Second, due to institutional changes (movement of capital in the international market) monetarism (which proposed control of monetary aggregates, Friedman, 1968) was displaced by the Austrian School's monetary approach, reformalized in the New Classical Consensus (which rejects the conventional treatment of the quantity theory of money). The latter view is presented on the basis of a model where the money market is replaced by the interest rate, which is determined by a reaction function of the central bank (Hüfner, 2004) that deploys monetary policies aimed at stabilizing prices. This approach retains the postulate of the 'Treasury Perspective' 
(first raised in the 1930s), which is completely opposite to fiscal deficits and in favor of the reduction of wages (Hawtrey, 1913).

In parallel with the dominant theories, alternative economic visions were developed that incorporate the dynamic condition of the capitalist economy and the trajectories of economic processes, and despite being less mathematized or formalized, have a broader analytical perspective that contains evolutionary processes and essential transformations, which originate in breaks and crises, accompanied by a process of gradual abandonment of equilibrium. From this alternative framework the various visions of effective demand were developed, led by J.M. Keynes (1936), M. Kalecki (1984), H. Minsky (1986), the Circuitists (Lavoie, 1992; Rochon, 1999), among others, ${ }^{1}$ and at the present time a large number of economists, under the aegis of financialization, are seeking to understand the genesis of the economic and financial breaks that triggered the Second Great Financial Crisis (2008), which has not yet been able to lay the groundwork of a new organization capable of restoring growth to all capitalist economies.

In the heterodox school of economic thought there is consensus that the dominant capitalist system is eminently monetary, with uncompetitive market structures that generate the accumulation of debts, imbalances between demand and supply and concentration of income, which is governed by the unequal distribution of wealth and income, and which taken together can slow economic growth through economic downturns, financial crises and even deep recessions.

The common denominator of this book is its adoption of the analytical framework of heterodox theory. It assumes that the capitalist system works on the basis of inherent disequilibria, which, it should be emphasized, are not caused by market failures, incomplete information or policy mistakes, and nor by external elements or shocks. On the contrary, the imbalances are structural, and are part of social arrangements with different interest or power groups that have the ability to determine the productive and financial structures, control the size of the surplus and - most significantly of all - influence its distribution between social classes and within subclasses. This is accompanied by the generation of a large debt, which gives rise to an interesting discussion on the impact of the financial system on the size and distribution of the surplus.

It may be added that the imbalances are not just the result of asymmetrical power relations between capital, on the one hand, and labor, on the other. The unequal power between countries should be considered, where some acquire hegemonic power (the USA) that allows them to appropriate the surpluses generated by others, leading to structural imbalances in their external accounts. The conquest of economic hegemony rests with 
the country's ability to impose its signs of value (the international currency of account, nowadays the US dollar) in international trade transactions and the global payments system; these may be accompanied by regional powers (for example, Germany in the eurozone) that are distinguished by their ability to influence the movement of capital, goods prices, and to determine economic policy (especially monetary policy). Furthermore, the hegemonic countries have the power to impose conditions on the bailout programs for countries in crisis. This further increases the extraction of surpluses, and results in increased inequality between the distribution of surpluses on a global or regional level; more significantly still, it delays finding solutions to the crisis.

In this context, it is argued that economic theory must consider the key features of the development of contemporary capitalism that arise from major imbalances (between hegemonic economies and underdeveloped or peripheral countries) that guide economic processes. The current dominant capitalist mode is organized on the basis of the institutional changes imposed through deregulation and globalization. This process changed the global financial system, endogenizing the provision of money in the form of private debt, expressed under the hegemonic power sign value (US dollars), without institutions capable of functioning as lenders of last resort to governments, or applying regulations that limit the movement of capital between nations. This led to a disproportionate increase in international liquidity, which put the financial markets in a context of asymmetric powers, dominated by financial centers in developed countries (the USA and UK), deepening the imbalances.

Financial capital came to play the leading role in all factors of production, affecting the composition of production, the size of the accumulation and distribution of surpluses among social classes and among countries. As a result of this process, the concept of financialization was coined. There are many definitions of this concept and no clear agreement on its content and the spectrum it dominates. We refer to the frequently cited definition by Epstein (2005, p.5): 'financialization means the increasing role of financial motives, financial markets, financial actors and financial institutions in the operation of domestic and international economies'; although it should be noted that agreement is beginning to coalesce around the need to analyze the domination of finance capital from the perspective of the reproduction of the debt and how it affects the income generation and forms of debt (balance sheets) of the major players in modern capitalist societies (financial and especially non-financial corporations), and has increased trade in financial securities and their rotation (Seccareccia, 2012/2013; Toporowski, 2013).

The new international division of labor is another phenomenon 
particular to this period of economic organization. Its main feature was the decoupling of demand with regard to supply: the hegemonic country (the USA) specialized in financial services, deploying monetary policies that determine interest rates that govern the movement of international capital, which guarantees minimum prices to financial securities by attracting financial flows from around the world. In turn, the USA became the global engine of demand because it distributed manufacturing output among the developed economies of Europe and Asia, with the participation of the least developed economies on the lowest rungs of the production chains. Using global supply chains, real production was transferred to the international market, triggering permanent imbalances in the current and capital accounts.

The hegemonic country is characterized by structural deficits in its current account, accompanied by a permanent surplus in the capital account, especially in periods of instability, first, because it retained the ability to create debts accepted internationally in US dollars, and second, because many of the transactions were made in this currency. For their part, producing economies generated large surpluses in their current accounts and exported capital to developed countries, with the export sector becoming the most dynamic activity in these nations' output. In such an environment, developing and peripheral countries are left with a reduced domestic market that is highly dependent on external demand. Thus, economic crises in the hegemonic or dominant countries at a regional level, or changes to the origin of imports, cause severe economic crises in the least developed countries.

Another key element is that the finance-led model was based on the concentration of income, while competition among countries was generated by reducing wages, which, on the one hand, increased income appropriation by the capitalists (especially in the financial segment), and, on the other, resulted in processes of impoverishment and job insecurity for the workforce. This phenomenon has been widespread, affecting both developed (hegemonic) countries and developing countries, and has been partially neutralized by the debt that households acquire to maintain their level of consumption. The difference between countries lies in the depth and impact of this phenomenon. In the case of peripheral countries, income concentration is more severe because the main competitive element of their manufacturing production and exports (highly dependent on imports) was low wages, without deploying technological advances, or they exported raw materials without achieving robust and lasting surpluses in their current accounts. This forced these economies to import financial flows, which became another source of their high levels of indebtedness. In short, a very unequal income distribution was generated worldwide, 
accompanied by a growing indebtedness. With respect to higher-income countries with deep financial markets, income became concentrated in the highest strata (the top 1 percent of the population, see Piketty, 2014), while in the less developed countries, the participation of lower-income strata fell drastically.

This structure changed government intervention in the economy. The objectives of economic policy shifted from full employment, based on technological development and deepening of industrialization, to price stability and attracting foreign investment. In this context, public spending contracted and changed its composition, as public expenditure on investments with large multiplier effects fell. Primary surpluses appeared, together with increasing bond issues to stabilize interest and exchange rates, in which commercial banks played an important role that in turn financed governments, depending on the arrangements of the dominant institutions. As a result of this process, public debt increased, and accelerated in times of crisis, as governments had to take over unpaid private debt; this weakened public policies in their counter-cyclical dimension.

The key point arising from the above is that in this new economic policy environment it became harder to emerge from a crisis. Developed (hegemonic) countries used flexible monetary policies (quantitative easing) to restore the activity of financial markets and the profitability of their corporations, but were unable to increase either employment or wages, and also failed to create the conditions for sustained economic growth and leave the crisis behind. The developing and peripheral countries that needed bailouts were forced to deploy primary surpluses with public deficits. This forced them to reduce their level of growth to balance the current account in a context of lower exports, and to increase interest rates higher than the rest of the world and reduce the share of income of wage earners. Economic stagnation and unemployment are accompanied by lower social spending on health, education and so on, thus generating a generalized impoverishment of the lower-income strata, and deepening inequality in income distribution.

On the basis of the above we can assert that the historical period of deregulation and globalization (also known as the neoliberal period) that evolved in the last third of the last century, with domination of finance capital, is built on the basis of large disequilibria that cover all spheres and regions. These reproduce themselves and gradually build up in all nations as a result of the trade and financial imbalances of the hegemonic country, which have reached startling levels. The US prerogative of issuing the international unit of account is, in that context, an essential factor in the design of the international realignment, both for developed and developing capitalist countries. Although this system entered crisis in 2008, new ways 
of restoring growth and overcoming the widespread stagnation are still to be found.

An additional point to consider is that the financial bailouts supported by the 'Treasury Perspective' and currently applied in Europe have proved to have little effect. These are poised to gain strength in Latin American economies, in light of falling prices of raw materials, the region's main exports. In the 1980s, as a result of the foreign debt crisis, Latin America was subject to harsh experiences. The International Monetary Fund and the main creditors of the region imposed macroeconomic equilibria, reductions in public spending and current account surpluses, which led to a fall in economic growth (those years are known as the 'lost decade'), accompanied by major devaluations and inflationary processes that were resolved only by reducing the amount of debt (Brady Plan). The second foreign debt crisis, which began in 1994, showed the countries in the region that they could not rely on foreign borrowing. Subsequently, the region, in an environment of reduced government intervention in the economy and opening up of capital, has sought to strengthen its export capacity. This process maintained low levels of economic activity, highly influenced by the vagaries of international trade, and from 2014 confronted major challenges with the dramatic fall in the price of raw materials; to this was added the fact that the overvalued currencies serve as an anchor for prices.

Based on the above, we highlight some of the main problems of the current economic system.

First, it is necessary to restructure the financial system in order for it to become an essential factor in the recovery of productive activity in developed countries and developing and peripheral countries alike. In particular, the growing trade in financial securities that generated the financial inflation should be subject to international regulation to ensure liquidity not only to the developed economies, but also to developing and, in particular, peripheral countries.

Second, external imbalances should be limited by economic policies to reduce deficits. The key point is to recognize that growth models based on beggar-thy-neighbor are highly unstable and must be countered.

Third, the development of technological innovations and the expansion of the capital goods sector cannot be left entirely to private initiatives. Government spending has proved to be highly efficient with large multiplier effects, and financing policies aimed at activating the private sector have been successful in other periods.

Fourth, the increase of wages must be a concerted policy in economies and regions in order to strengthen domestic markets. Finally, as a fifth element, the government must deal with income inequality by imposing 
distributive tax policies, spending on education, health and so on, and in general combating poverty.

\section{I.1 STRUCTURE OF THE BOOK}

This book is divided into four parts, with a total of 14 chapters. Part I is titled 'Structural disequilibria in Europe: what to do?' and comprises three chapters. Chapter 1, 'A structural and monetary perspective of the euro crisis' by Riccardo Bellofiore, Francesco Garibaldo and Mariana Mortagua argues that the European crisis cannot be treated as a typical breakdown resulting from balance of payments problems and cumulative price differentials, and nor does it reflect neo-mercantilist strategies. From the authors' perspective, the European crisis should be discussed in light of the structural problems with the productive sector, considering the structural changes generated by the eurozone, which altered the ways of mobilizing capital and promoted accumulation.

Ma. Guadalupe Huerta presents Chapter 2, 'The big financial crisis and the European economic adjustment: a road toward the strengthening of the neoliberal agenda', where it is argued that the institutional design of the eurozone does not allow for the deployment of fiscal and monetary policies to overcome the crisis, which raises the need for a thorough analysis of European integration in terms of macroeconomic and social aspects, accompanied by an assessment of the economic policies necessary to restore growth.

Chapter 3, 'Debt deflation theory and the Great Recession' written by Domenica Tropeano and Alessandro Vercelli. On the basis of the theory of Irving Fisher, the chapter analyzes the accumulation of debt in the USA and Europe, emphasizing that the monetary policy deployed in the former did manage to save the banking system, and this did not happen in Europe due to the European Central Bank being less able to intervene in the economy, and the absence of an authority empowered to coordinate spending.

Part II of the book is titled 'The forces of disequilibria at work: their impact on growth' and comprises five chapters. Alan Cibils and Germán Pinazo present Chapter 4, 'The periphery in the productive globalization: a new dependency?' In this chapter the authors analyze the role of peripheral countries in what has been called the new international division of labor from two perspectives. First discussed is the theoretical debates centered on new growth theory, neostructuralism, and the renewed interest in structuralist and dependency theories. Second, a broad range of statistical aggregates are presented and analyzed. The authors conclude 
that there is justification for the use of dependency concepts for peripheral countries in today's international division of labor.

Chapter 5, 'Latin America in the new international order: new forms of economic organizations and old forms of surplus appropriation' is by Noemi Levy. It discusses the limits of growth in Latin America based on the disequilibria of the productive sector resulting from the financial and technological dependence of the region's countries, emphasizing that they are subject to a two-fold extraction of profit that hinders recirculation of surpluses to the economic system.

Chapter 6 by Carlos Rozo discusses the theme 'Inequality, technological change and worldwide economic recovery', arguing that the financial system becomes dysfunctional when it is uncoupled from the productive sector, because it promotes non-productive activities that produce large short-term profits, accompanied by technological development that leads to unemployment as a result of digital technology and artificial intelligence. In addition, the combination of these processes slows down economic growth and leads to income concentration, preventing full economic development.

Alma Chapoy in Chapter 7 addresses the issue of 'Global disequilibria and the inequitable distribution of income', focusing on the income inequality generated by the disconnect between the financial and productive sectors, which is reflected in growing current account imbalances and large cross-border transactions, explained by the predominant monetary asymmetries in the current capitalist period, generated by the USA that holds the privilege of being the sole issuer of international money.

The final chapter in Part II is 'Financialization, crises and economic policy' by Hassan Bougrine and Louis-Philippe Rochon, who argue that the financial and economic crisis that began in 2007 is part of a general breakdown in the corporate capitalist order that affects real and financial sectors alike. They identify two practices that have generated profound changes in the capitalist system, which altered the practices of financial and banking institutions, enabling financiers to concentrate their wealth independently of the productive sector. This has combined with austeritybased economic policies that have caused productive activity to stagnate below full employment levels.

Part III of the book is titled 'Disequilibria in the Mexican economy: the export growth model, economic stagnation and labor precarization' and includes three chapters. In Chapter 9, 'The limits of the export-led growth model: the Mexican experience', Etelberto Ortiz analyzes the consequences of the export model that placed manufacturing at the center of international trade in the Mexican economy, without creating linkages between traditional and leading productive sectors, and without 
establishing economic policies that strengthen the manufacturing sector. In light of a combination of theories, it analyzes the limitations of economic growth and possible alternatives to promote successful economic growth are reviewed.

In Chapter 10, Alejandro Álvarez and Sandra Martínez present 'The Mexican economy in 2014: between crisis, free trade, social devastation and labor precarization', delineating two central arguments. First, the effects of prolonged application of neoliberal formulas in public policies and second, the impact on workers' wages of labor and working conditions of developed and developing economies. These issues are discussed in light of the various trade agreements promoted by the USA and Mexico after the 2008 crisis that served the USA in regaining its hegemony and the links to the Mexican social conditions, highlighting the social devastation that has been taken place in recent years. Particular attention is given to the multi-regional integration that deepens the free trade programs by means of various legal and political instruments: the Trans-Pacific Partnership (TPP), the Trans-Atlantic Trade and Investment Partnership (TTIP) and the Trade in Services Agreement (TISA).

Luis Kato is the author of Chapter 11, 'The accumulation mode of production in Mexico and the economic structure of the manufacturing industry'. He discusses the stagnation of productivity of the workforce in relation to the dominance of large corporations that are connected to global commodity chains and use global competitive advantages to maximize profits; meanwhile, small and medium enterprises compete on the basis of lower costs (wages), which reduces the growth of accumulation and productivity.

The final part of the book, 'Disequilibria in Mexico: the financial and fiscal trap', examines the fiscal and financial traps that have been deployed in the Mexican economy in the period of financialization. There are three chapters. Chapter 12 by Teresa López and Eufemia Basilio is concerned with 'Economic growth and financial development in Mexico: from a virtuous circle of a bidirectional causality to financial subordination'. It develops the theme of bank lending to non-financial activities in the context of the Mexican economy between 1990 and 2013. An empirical and econometric assessment shows that deregulation and globalization, instead of increasing savings, caused the banking system to lose sight of its core activity, which is the financing of production. On this basis, the authors assert the need to establish regulatory mechanisms to ensure financial resources for production.

Christian Domínguez and Juan Marroquín in Chapter 13, 'Private sector finance in the era of deregulation and economic openness: Mexico 2000-2014', analyze the trends in the financing of the non-financial private 
sector in Mexico following deregulation and economic openness. They argue that these processes shaped monetary and fiscal policies that maintain high interest rates making financing more expensive and reducing access to it for companies operating in the domestic market. The authors find that despite reducing interest rate differentials with the US economy, these nevertheless function as a factor that limits access to financing, particularly for small and medium enterprises in the services and commercial sectors.

Finally, Chapter 14 is 'Pro-cyclical fiscal policy and the fiscal support of the Mexican monetary policy’ by Luis Á. Ortiz. He argues that monetary policy based on a system of fiscal and financial targets generates a contraction in capital spending and higher quasi-fiscal and financial costs. This is due to an oversupply of foreign exchange causing sterilized interventions in the foreign exchange market. As a result, it is noted that the behavior of the Bank of Mexico, in exercising its autonomy in pursuit of an inflation target, has an anti-democratic bias, not only due to the fiscal support it receives from the government, but also because it prevents the countercyclical exercise of fiscal policy.

\section{NOTE}

1. We are not including the evolution of Marxist theory here.

\section{REFERENCES}

De Vroey, M. (1999), 'J.R. Hicks on equilibrium and disequilibrium. Value and capital revisited', History of Economics Review, 29, 31-44.

Epstein, G.A. (2005), 'Introduction', in G. Epstein (ed.), Financialization and the World Economy, Cheltenham, UK and Northampton, MA, USA: Edward Elgar, pp. 3-16.

Friedman, M. (1968), 'The role of monetary policy', American Economic Review, LVIII(1), 1-17.

Goodfriend, M. (2002), 'Monetary policy in the new neoclassical synthesis: a primer', International Finance, 5(2), 165-91.

Hawtrey, R. (1913), Good and Bad Trade: An Inquiry into the Causes of Trade Fluctuations, London: Kessinger Publishing.

Hicks, J.R. (1946), Value and Capital, 2nd edn, Oxford: Clarendon Press.

Hüfner, F. (2004), Foreign Exchange Intervention as a Monetary Policy Instrument: Evidence from Inflation Targeting Countries, Centre for European Economic Research, ZEW Economic Studies 23, Heidelberg: Physica-Verlag.

Kalecki, M. (1984), 'Teoriìa de la dinaìmica econoìmica. Ensayos sobre los movimientos ciìclicos y a largo plazo de la economiìa capitalista' ('Theory of 
economic dynamics: an essay of cyclical and long-run changes in capitalist economies'), Fondo de Cultura Econoìmica, Mexico.

Keynes, J.M. (1936), The General Theory of Employment Interest, and Money, reprinted in 1964, London: Harvest/Harcourt.

Lavoie, M. (1992), Foundations of Post-Keynesian Economic Analysis, Aldershot, UK and Brookfield, VT, USA: Edward Elgar.

Lucas, R. (1976), 'Econometric policy evaluation: a critique', Carnegie-Rochester Conference Series on Public Policy, 1, 19-46.

Minsky, H. (1986), Stabilizing an Unstable Economy, New Haven, CT: Yale University Press.

Piketty, T. (2014), Capital in the Twenty-first Century, Cambridge, MA: Belknap Press.

Rochon, L.-P. (1999), Credit, Money, and Production: An Alternative Post-Keynesian Approach, Cheltenham, UK and Northampton, MA, USA: Edward Elgar.

Seccareccia, M. (2012/2013), 'Financialization and the transformation of commercial banking: understanding the recent Canadian experience before and during the international financial crisis', Journal of Post Keynesian Economics, 35(2), $277-300$.

Toporowski, J. (2013), 'International credit, financial integration and the euro', Cambridge Journal of Economics, 37(3), 571-84.

Woodford, M. (2003), Interest and Prices. Foundation of a Theory of Monetary Policy, Princeton, NJ: Princeton University Press.

Woodford, M. (2009), 'Convergence in macroeconomics: elements of the new synthesis', American Economic Journal, 1(1), 267-79. 
Noemi Levy and Etelberto Ortiz - 9781785364761 Downloaded from PubFactory at 04/26/2023 05:15: 09AM 